\title{
ECTRODACTILIA EM CÃO (Canis domestica)
}

\author{
ECTRODACTILIA IN DOG (Canis domestica)
}

\section{Daniela Oliveira $^{1}$ Silvana Martinez Baraldi Artoni ${ }^{2}$}

\section{- RELATO DE CASO -}

\section{RESUMO}

O presente trabalho relata o caso de uma cadela sem raça definida, adulta, com deformidade na região distal do membro torácico esquerdo, a qual consistia de duplicidade do osso acessório do carpo, aplasia do primeiro carpiano, ausência dos ligamentos interósseos entre o terceiro e o quarto dígitos, alterações ósseas no quarto dígito e presença de um dígito supranumerário incompleto adjacente ao quarto dígito. Após análise dos defeitos concluiu-se tratar de uma malformação congênita, hereditária em cães, denominada ectrodactilia, associada à existência de um dígito supranumerário.

Palavras-chave: ectrodactilia, cão, anatomia.

\section{SUMMARY}

This paper describes a case of an adult mongrel bitch with a deformity in the distal area of the left forelimb, which was based on duplicity of the accessory carpal bone, aplasia of the first carpal bone, nonexistence of the interosseus ligament between digits 3 and 4, bony alterations in digit 4 and presence of an incomplete supernumerary digit adjacent to digit 4. After analysis of defects it was concluded to be a hereditary congenital malformation named ectrodactyly, associated to the existence of a supernumerary digit.

Key words: ectrodactyly, dog, anatomy.

\section{INTRODUÇÃO}

As malformações congênitas de membros podem consistir de deformidades tais como aplasia, "clubfoot", focomelia e ectrodactilia (MANN et al., 1992).

Ectrodactilia é caracterizada pela separação anormal entre os dígitos, podendo estar acompanhada de aplasia e hipoplasia de vários ossos carpianos e metacarpianos, duplicação de dedos, fusão de metacarpianos e luxação da articulação do cotovelo (JUBB et $\boldsymbol{a l}$., 1988). FREY \& WILLIAMS (1995) definem ectrodactilia como uma malformação rara descrita como uma deficiência paraxial longitudinal de um ou mais dos elementos individuais da porção distal do membro de um embrião em desenvolvimento, geralmente associada a luxação congênita do cotovelo e a retração de tecidos moles e dígitos. De acordo com MONTGOMERY et al. (1989) esta afecção já foi descrita em cães, gatos, bovinos e seres humanos. As causas deste defeito podem ser genética, através de um gene dominante em cães e gatos (JUBB $\boldsymbol{e t}$ al., 1988) ou teratogênica em humanos e camundongos, destacando-se os anticonvulsivantes (ácido valpróico, dimetadiona, valproato de sódio, difenilidantoína) (COLLINS et al., 1991; AULTHOUSE \& HITT, 1994), cocaína (FANTEL et al., 1992) e interação aspirina-álcool (PADMANABHAN \& PALLOT, 1995).

KELLER \& CHAMBERS (1989) relataram o caso de um cão Doberman Pinscher de 5 meses de idade e $20,5 \mathrm{~kg}$ com uma malformação do

\footnotetext{
${ }^{1}$ Médico Veterinário, Mestrando em Cirurgia Veterinária, Faculdade de Ciências Agrárias e Veterinárias (FCAV), Universidade Estadual Paulista (UNESP)

${ }^{2}$ Médico Veterinário, Professor Assistente, Doutor, Departamento de Morfologia e Fisiologia Animal, FCAV, UNESP, 14888-000, Jaboticabal, SP. E-mail: smbart@fcav.unesp.br. Autor para correspondência.
} 
braço direito. O defeito mais aparente era uma completa separação óssea e de tecidos moles, que se localizava entre o segundo e o terceiro dígitos até o carpo. A radiografia revelou alterações adicionais como separação óssea que continuava através do carpo, ossos cárpicos hipoplásicos e malformados e subluxação do cotovelo direito por causa da má sustentação do peso sobre o carpo. Estas alterações congênitas resultaram em uma articulação cárpica instável, dificultando a deambulação. Para correção, foi realizada artrodese rádio-metacárpica, utilizando fixação com placa, mas o animal apresentou claudicação intermitente durante 8 meses após a intervenção em decorrência de uma má articulação do cotovelo.

MONTGOMERY et al. (1989) e FREY \& WILLIAMS (1995) recomendaram a ováriohisterectomia em cães e gatos ectrodáctilos, como prevenção da propagação deste defeito, devido ao caráter hereditário nestas espécies.

O objetivo deste trabalho consistiu em descrever anatomicamente um caso de ectrodactilia associado a outros defeitos congênitos presentes em uma cadela.

\section{MATERIAL E MÉTODOS}

Uma cadela sem raça definida (SRD), adulta, de porte médio, hígida, proveniente do canil experimental do Centro de Pesquisas Parasitológicas (CPPar) da Faculdade de Ciências Agrárias e Veterinárias de Jaboticabal - SP (FCAVJ - UNESP) apresentava claudicação no membro torácico esquerdo, sendo que o apoio era feito principalmente pelo segundo e terceiro dígitos. $\mathrm{O}$ animal foi submetido à eutanasia e o membro torácico esquerdo foi retirado e conservado em solução de formol a $10 \%$ para posterior dissecação e observação das estruturas anatômicas. A pele e parte dos tecidos moles (músculos, tendões e ligamentos) foram retirados e a peça constituída pelos carpos, metacarpos e falanges foi separada e submetida a exame radiográfico. Este conjunto foi fervido numa solução de água oxigenada 10 volumes para a melhor visualização das peças ósseas. Foi realizada a documentação fotográfica através de uma câmera fotográfica Pentax ${ }^{\circledR}$, utilizando um filme colorido Fujicolor Superia, Asa 100.

\section{RESULTADOS E DISCUSSÃO}

Durante o exame físico, notou-se uma deformidade na porção distal do membro torácico esquerdo, que consistia na separação extensa dos tecidos moles (pele, músculos, tendões e ligamentos) entre o terceiro e o quarto dígitos, e presença de um dígito supranumerário adjacente ao quarto dígito (Figuras 1A e 1B). Após a eutanásia do animal e a separação do membro acometido, os tecidos cutâneo e muscular foram retirados. Não foram observadas alterações ósteo-articulares no úmero, rádio e ulna. No entanto, vários defeitos foram encontrados na região distal do membro. Observou-se duplicidade do osso acessório do carpo, sendo que um deles se articulava com o osso ulnar do carpo e o outro, com o radial do carpo (Figura 1D). SISSON (1986) descreveu o osso acessório do carpo normal como sendo único, que se articula com a ulna e o ulnar do carpo. O primeiro carpiano encontrava-se aplásico (Figuras 1C e 1D). JUBB et al. (1988) observaram que há casos de ectrodactilia que podem ser acompanhados de aplasia e hipoplasia de ossos carpianos. O segundo carpiano apresentava uma saliência medial, que poderia ser um resquício do primeiro carpiano (Figura 1C).

O ligamento interósseo, localizado entre o terceiro e o quarto metacarpianos, estava ausente, levando à separação anormal entre o terceiro e o quarto dígitos. MONTGOMERY et al. (1989) e KELLER \& CHAMBERS (1989) encontraram características semelhantes em uma cadela de 3 meses e outra de 5 meses.

$\mathrm{O}$ terceiro dígito (Figura 1A) apresentava retração dos tecidos moles (músculos, tendões e ligamentos), morfologia semelhante à observada por FREY \& WILLIAMS em 1995. Radiograficamente, observou-se na extremidade distal do terceiro metacarpiano um estreitamento e conseqüente diminuição da superfície articular (Figura 1E), diferentemente da descrição de SISSON (1986), em que o autor descreve as superfícies articulares distais do segundo ao quinto metacarpiano normais como uma cabeça, a qual possui um ressalto sagital na superfície palmar. Notou-se também ausência dos ossos sesamóides palmares neste dígito, além de uma ausência de concavidade na superfície da falange proximal que se articula com o osso metacarpiano, e na tróclea, que se articula com a falange média (Figura E). SISSON (1986) relatou, em cães normais, a presença de nove ossos sesamóides palmares, encontrados aos pares em cada articulação metacarpofalângica dos dígitos principais, e um único sesamóide na articulação do primeiro dígito (excepcionalmente estão presentes dois). O mesmo autor relatou que as falanges proximais possuem em suas epífises proximais uma superfície côncava para articulação com o osso metacárpico, e as epífises distais apresentam uma tróclea para articulação com a falange média. 


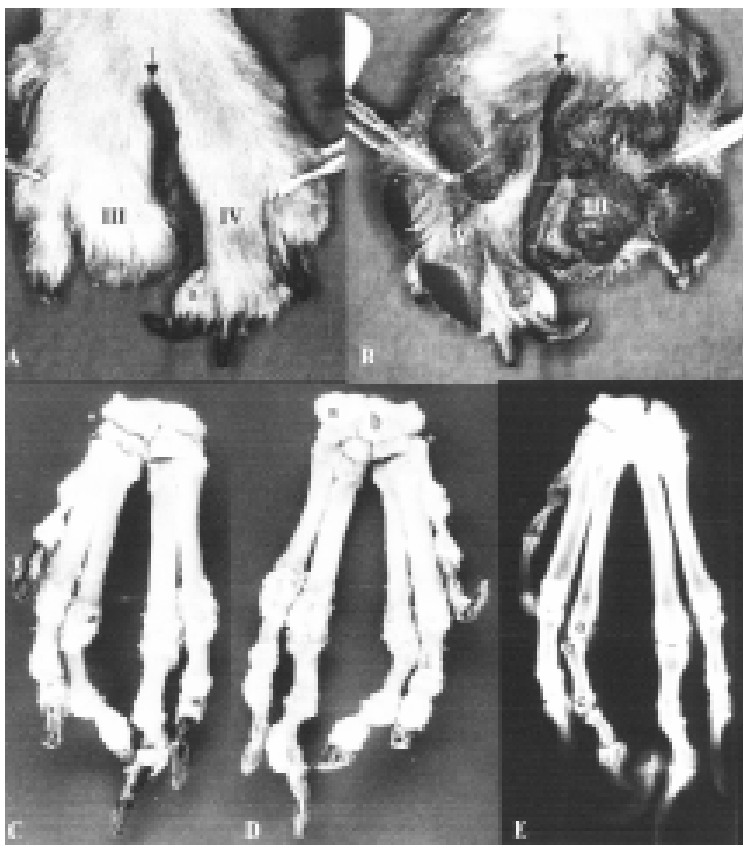

Figura 1 - Deformidade da extremidade distal do membro torácico esquerdo de cadela.

A- Vista dorsal. Nota-se a extensa separação (seta) dos tecidos moles entre o terceiro (III) e o quarto (IV) dígitos e presença de um dígito supranumerário (a). B- Vista palmar. Nota-se a extensa separação dos tecidos moles entre o terceiro e o quarto dígitos (seta) e presença de um dígito supranumerário (a).

C- Vista dorsal.Observa-se a ausência do primeiro carpiano $(*)$ e a presença de uma saliência medial no segundo carpiano (a), que sugere ser um resquício do primeiro carpiano. O dígito supranumerário foi retirado, pois encontrava-se preso apenas pelo tecido cutâneo, e não se articulava com nenhuma estrutura óssea.

D- Vista palmar. Há duplicidade do acessório do carpo (a, b), sendo que (a) se articula com o ulnar do carpo e (b) se articula com o radial do carpo. Nota-se também a ausência do primeiro carpiano $(*)$.

E- Imagem radiográfica dorsopalmar. Nota-se estreitamento na extremidade distal do terceiro metacarpiano com diminuição da superfície articular, além da ausência dos sesamóides neste dígito (a). Observa-se também uma ausência de concavidade (b) na superfície da falange proximal, que se articula com o respectivo metacarpiano, e na tróclea (c), que se articula com a falange média. $\mathrm{O}$ dígito supranumerário (d) não se articula com nenhuma estrutura óssea.

O dígito supranumerário localizava-se adjacente ao quarto dígito e, após a retirada dos tecidos moles, foi confirmado que este era formado apenas pela falange distal e preso ao quarto dígito através do tecido cutâneo (Figura 1E).

\section{CONCLUSÃO}

Ao analisar o conjunto das características morfológicas encontradas na mão da cadela, concluiu-se tratar-se de um caso de ectrodactilia associado à presença de um dígito supranumerário incompleto adjacente ao quarto dígito.

\section{REFERÊNCIAS BIBLIOGRÁFICAS}

AULTHOUSE, A.L, HITT, D.C. The teratogenic effects of valproic acid in human chondrogenesis in vitro. Teratology, v.49, n.3, p.208-217, 1994.

COLLINS, M.D., WALLING, K.M., RESNICK, E., et al. The effect of administration time on malformations induced by three anticonvulsant agents in C57BL/6J mice with emphasis on forelimb ectrodactyly. Teratology, v.44, n.6, p.617-628, 1991.

FANTEL, A.G., BARBER, C.V., CARDA, M.B., et al. Studies of the role of ischemia/reperfusion and superoxide anion radical production in the teratogenicity of cocaine. Teratology, v.46, p.293-300, 1992.

FREY, M, WILLIAMS, J. What is your diagnosis? [Ectrodactyly in a Chow Chow dog]. J Am Vet Med Assoc., v.206, n.5, p.619-620, 1995.

JUBB, K.V.F., KENNEDY, P.C., PALMER, N. Patología de los animales domésticos. 3.ed. Uruguay: Hemisfério Sur, 1988. Cap.1: Huesos y articulaciones: p.1-167.

KELLER, W.G., CHAMBERS, J.N. Antebrachial metacarpal arthrodesis for fusion of deranged carpal joints in two dogs. J Am Vet Med Assoc., v.195, n.10, p.1382-1384, 1989.

MANN,R.W., WIERCINSKA, A., SCHEFFRAHN, W. Distal phocomelia of the forearm in a thirteenth-century skeleton from Poland. Teratology, v.45, n.2, p.139-144, 1992.

MONTGOMERY, R.D., MILTON, J.L., MANSFIELD, P.D., $\boldsymbol{e}$ al. What is your diagnosis? [Ectrodactyly in a dog]. J Am Vet Med Assoc., v.194, n.1, p.120-121, 1989.

PADMANABHAN, R,' PALLOT, D.J. Aspirin-alcohol interaction in the production of cleft palate and limb malformations in the TO mouse. Teratology, v.51, n.6, p.404-417, 1995 .

SISSON, S. Osteologia do carnívoro. In: GETTY, R. Anatomia dos animais domésticos. Rio de Janeiro: Guanabara Koogan, 1986. Cap.48. p.1337-1412. 